\title{
Response of the Indian Pharma Sector to Economic Policy Uncertainty Shocks
}

Prof. Ashwin R. John, Assistant Professor,Department of Management Studies- PG,Acharya Bangalore B-School, Bengaluru, Karnataka, India, Ph: +91 8884719191, Email: ashwinjohn2000@gmail.com, ashwinjohn@acharyabbs.ac.in

\begin{abstract}
This paper analyses the impact of monthly changes in EPU index of India (constructed by Baker, Bloom and Davis in 2012) on the BSE Healthcare Index returns that is representative and consists primarily of the pharma sector stocks. Impulse Response Analysis is carried out to determine the response of BSE Healthcare Index returns to the shocks in the EPU Index.

The paper has the objective to find out if there is a causal relationship between EPU index and the returns on the BSE Healthcare Index. The results show that there is evidence of a causal relationship between EPU index and the returns on BSE Healthcare Index as seen from the results of the Granger Causality tests and the Impulse Response Function analysis.
\end{abstract}

Keywords: Economic Policy Uncertainty, Granger Causality, Impulse Response, Robust Regression, Causal, Vector Autoregression, Co-integration

\section{Introduction}

As per a report by Price Waterhouse Coopers, India's pharma sector ranks fourth in terms of volume of sales with a share of $8 \%$ in global sales. If this were not enough, it produces $20-24 \%$ of the globe's generic drugs. These statistics draw the attention towards the promising healthcare sector in India.

Economic policy uncertainty (EPU) has shown to adversely affect economic growth and slows down investment flow. Pindyck (1990) has stated that investments are largely irreversible and therefore firms would hold investment decisions unless they foresee stability and credibility in terms of state policy. Hermes and Lensink (2001) on the other hand have found that policy uncertainty encourages domestic investors to withdraw their investments from the domestic market and invest in foreign markets leading to accelerated capital flight. Given these findings, if Indian pharma sector has to grow as expected, it is imperative to ensure a stable policy climate so that the investments, both domestic and foreign keep flowing into the sector.

The paper has the objective to find out if there is a causal relationship between EPU index and the returns on the BSE Healthcare Index. This paper analyses the impact of monthly changes in EPU index of India (constructed by Baker, Bloom and Davis in 2012) on the BSE Healthcare Index returns that is representative and consists primarily of the pharma sector stocks. Impulse Response Analysis is carried out to determine the response of BSE Healthcare Index returns to the shocks in the EPU Index. Also the relationship between BSE Healthcare Index returns and the EPU Index is tested when mediated by MSCI India Value Weighted Index returns that are representative of the Indian stock market. Value weighted index is used to avoid the inefficiencies of market-cap weighting, since such an index is regularly rebalanced to weigh heavily those stocks that are trading at large discounts to market values, unlike the market cap indices that heavily weigh the expensive stocks. 


\section{Data and Methodology}

The monthly data analysed spans the period from May 2008 until April 2017. The EPU Index values are sourced from www.policyuncertainty.com, the BSE Healthcare Index values from www. bseindia .com and the $\mathrm{MSCl}$ India Value Weighted Index valuesfrom www.msci.com.

Vector Autoregression (VAR) analysis is carried out using a system of equations outlined below on the three variables - BSE_Healthcare Index returns (BSE_Health) representative of the pharma sector, first differenced EPU Index values (diffEPU) and $\mathrm{MSCl}$ India Value Weighted Index returns (MSCI). Later, the impulse response functions of BSE_Health to the impulses from diffEPU are determined.

R_BSE_Health $=C 1+\sum_{\mathrm{i}=1}^{\mathrm{n}} \alpha_{\mathrm{i}} \Delta \mathrm{EPU}_{\mathrm{t}-\mathrm{i}}+\sum_{\mathrm{i}=1}^{\mathrm{n}} \beta_{\mathrm{i}} \mathrm{R}_{-} \mathrm{MSCI}_{\mathrm{t}-\mathrm{i}}+\sum_{\mathrm{i}=1}^{\mathrm{n}} \gamma_{i} \mathrm{R}_{-}$BSE_Health $\mathrm{t}_{\mathrm{t}-\mathrm{i}}+\varepsilon_{\mathrm{t}}$ $\Delta \mathrm{EPU}_{\mathrm{t}}=\mathrm{C} 2+\sum_{\mathrm{i}=1}^{\mathrm{n}} \mathrm{a}_{\mathrm{i}} \Delta \mathrm{EPU}_{\mathrm{t}-\mathrm{i}}+\sum_{\mathrm{i}=1}^{\mathrm{n}} \beta_{\mathrm{i}} \mathrm{R}_{-} \mathrm{MSCI}_{\mathrm{t}-\mathrm{i}}+\sum_{\mathrm{i}=1}^{\mathrm{n}} \gamma_{\mathrm{i}} \mathrm{R}_{-}$BSE_Health $\mathrm{H}_{\mathrm{t}-\mathrm{i}}+\varepsilon_{\mathrm{t}}$

R_MSCI $=C 3+\sum_{i=1}^{n} a_{i} \Delta E P U_{t-i}+\sum_{i=1}^{n} \beta_{i} R \_M S C I_{t-i}+\sum_{i=1}^{n} \gamma_{i} R \_B S E \_H e a l t h h_{t-i}+\varepsilon_{t}$

R_BSE_Health $\mathrm{t}_{\mathrm{t}}=$ Returns on BSE_Health values in month $\mathrm{t}$ R_BSE_Health $\mathrm{t}_{\mathrm{t}-\mathrm{I}}=$ Returns on BSE_Health values in month $\mathrm{t}-\mathrm{i}$ $\triangle \mathrm{EPU}_{\mathrm{t}}=$ diffEPU values in month $\mathrm{t}$

$\triangle E P U_{t-i}=$ diffEPU values in month $\mathrm{t}-\mathrm{i}$

$\mathrm{R}_{-} \mathrm{MSCl}_{\mathrm{t}}=$ Returns on $\mathrm{MSCl}$ values in month $\mathrm{t}$

$\mathrm{R}_{-} \mathrm{MSCl}_{\mathrm{t}-\mathrm{I}}=$ Returns on $\mathrm{MSCl}$ values in month $\mathrm{t}-\mathrm{i}$

$\alpha_{i}, \beta_{i}$ and $\gamma_{i}=$ estimators

Granger Causality tests are carried out to determine if the changes in diffEPU granger cause changes in $\mathrm{BSE}$ _Health and if changes in $\mathrm{MSCl}$ granger cause changes in BSE_Health.

Additionally, robust regressions are run to determine the effect of diffEPU on BSE_Health returns and the mediating effect of $\mathrm{MSCl}$ returns. Robust regression techniques provide estimators that ignore the effect of outliers and present estimates that are more representative of the sample data.
Granger Causality tests are carried out to determine if the changes in diffEPU granger cause changes in BSE_Health and if changes in $\mathrm{MSCl}$ granger cause changes in BSE_Health.

Additionally, robust regressions are run to determine the effect of diffEPU on BSE_Health returns and the mediating effect of $\mathrm{MSCl}$ returns. Robust regression techniques provide estimators that ignore the effect of outliers and present estimates that are more representative of the sample data.

\section{Analysis and Results}

Before proceeding with the VAR analysis, the Augmented Dickey Fuller test was conducted on each of the three variables and the results are in Table 1. As per the results, all the three variables are found to be stationary.

A Vector Autoregression (VAR) analysis was performed on the 3 variables - BSE_Health, diffEPU and $\mathrm{MSCl}$. Before proceeding with the analysis, the optimal lag was selected using the Schwarz's Information criterion (SC), Akaike Information criterion (AIC) and Hannan-Quin Information criterion (HQ). All the three tests suggested one lag to be used as optimal.

Next, the Johansen test was run to check for any cointegrating relationships between the variables. Table 7 reports the results and the low $p$-value indicate that the null hypothesis of no co-integration can be rejected. Therefore, there is co-integration amongst the variables that indicates long run equilibrium. In this case, a Vector Error Correction Model (VECM) as reported in Table 8 was estimated.

The VECM was used to generate the Orthogonal Impulse Response Function (IRF) as detailed in Table 3 and plotted as seen in Figure 1. The IRF is orthogonalised as the underlying shocks are less likely to occur in isolation but rather as contemporaneous correlation between the components of the error process of the variables involved. diffEPU is the impulse variable and BSE_Health is the response variable. As seen in Table 3 from the coefficients, BSE_Health negatively responds to shocks in diffEPU 
in second, fourth, fifth, sixth, seventh, eighth, ninth, tenth and eleventh months. This indicates the inverse nature of relationship between BSE_Health and diffEPU.

The correlation between the three variables is reported in Table 2. The Granger Causality tests reported in Table 4 show that the null hypothesis can be rejected at $1 \%$ significance level ( $p$-value $=$ 0.008652 ) and it can hence be stated that diffEPU granger causes BSE_Health which reinforces the results of IRF in Table 3. Therefore policy uncertainty has a bearing on the BSE Healthcare Index and a reduced EPU index can boost the values of the healthcare index. Also when it comes to $\mathrm{MSCl}$ and BSE_Health, the null hypothesis cannot be rejected as the $\mathrm{p}$-value is high at 0.2516 . Therefore, $\mathrm{MSCl}$ does not granger cause BSE_Health. This signifies that the first differenced EPU Index values are more helpful to forecast the BSE Healthcare Index returns as compared to the returns on $\mathrm{MSCl}$ India Value Weighted Index.

Further, Robust Regression was carried out, the results of which are outlined in Tables 5 and 6 . Robust Regression techniques reduce the impact of outliers (that are assigned very low weights) and thereby provide estimators that are more representative of the sample data. The regression results in Table 5 show that diffEPU negatively affects BSE_Health and the diffEPU co-efficient -0.0002 holds with $11 \%$ significance level. Also, when mediated by $\mathrm{MSCl}$, the relationship between diffEPU and BSE_Health becomes insignificant. As seen in Table 6, the results of equation BSE_Health diffEPU $+\mathrm{MSCl}$, show that the coefficient of diffEPU is insignificant with a very high $\mathrm{p}$-value. The coefficient of $\mathrm{MSCl}$ is significant and positively affects BSE_Health.The results of Robust Regression are contrary to those of the Granger Causality tests. This gives credence to the statement that regression analysis does not necessarily imply a causal relationship between the variables. Both the Granger Causality tests and the IRF analysis reinforce the relationship between the returns on BSE Healthcare Index and the first differenced EPU Index values.

Table 1: Augmented Dickey-Fuller Test Critical Values

\begin{tabular}{|c|c|c|c|c|c|c|}
\hline Variable & $\begin{array}{l}\text { T-sta } \\
\text { tistic }\end{array}$ & $1 \%$ & $5 \%$ & $10 \%$ & $\mathrm{HO}$ & Conclusion \\
\hline diffEPU & -9.718 & -3.46 & -2.88 & -2.57 & $\begin{array}{l}\text { The series } \\
\text { is non-sta } \\
\text { tionary }\end{array}$ & $\begin{array}{l}\text { reject null at } \\
1 \% \text { signifi } \\
\text { cance level }\end{array}$ \\
\hline $\begin{array}{l}\mathrm{BSE}_{-} \\
\text {Health }\end{array}$ & -3.0946 & $5-3.46$ & -2.88 & -2.57 & $\begin{array}{l}\text { The series } \\
\text { is non-sta } \\
\text { tionary }\end{array}$ & $\begin{array}{l}\text { reject null at } \\
5 \% \text { signifi } \\
\text { cance level }\end{array}$ \\
\hline $\mathrm{MSCl}$ & -7.4428 & $3-3.46$ & -2.88 & -2.57 & $\begin{array}{l}\text { The series } \\
\text { is non-sta } \\
\text { tionary }\end{array}$ & $\begin{array}{l}\text { reject null at } \\
1 \% \text { Signifi } \\
\text { cance level }\end{array}$ \\
\hline
\end{tabular}

Table 2: Correlations

\begin{tabular}{|llll|}
\hline Variable & diffEPU & BSE_Health & MSCl \\
\hline diffEPU & 1.00 & -0.07 & -0.37 \\
BSE_Health & -0.07 & 1.00 & 0.52 \\
MSCl & -0.37 & 0.52 & 1.00 \\
\hline
\end{tabular}

Table 3 : The Orthogonal Impulse Response Functions of BSE_Health returns to shocks in diffEPU

\begin{tabular}{|llll|}
\hline $\begin{array}{l}\text { Horizon } \\
\text { (In months) }\end{array}$ & \multicolumn{2}{l}{$\begin{array}{l}\text { Impulse } \\
\text { response } \\
\text { coefficients }\end{array}$} & Lower Band \\
\hline 1 & 0.00000 & 0.00000 & 0.00000 \\
Band & \\
2 & -0.01577 & -0.02551 & -0.00265 \\
3 & 0.00293 & -0.01163 & 0.01578 \\
4 & -0.00724 & -0.01441 & 0.00171 \\
5 & -0.00523 & -0.01454 & 0.00310 \\
6 & -0.00469 & -0.01335 & 0.00381 \\
7 & -0.00493 & -0.01332 & 0.00412 \\
8 & -0.00507 & -0.01416 & 0.00316 \\
9 & -0.00495 & -0.01372 & 0.00358 \\
10 & -0.00497 & -0.01354 & 0.00361 \\
11 & -0.00498 & -0.01378 & 0.00342 \\
\hline
\end{tabular}


Table 4: Granger Causality Tests

0 : diffEPU do not Granger-cause BSE_Health

F-Test $=7.0273, \mathrm{df1}=1, \mathrm{df2}=206, \mathrm{p}$-value $=$ 0.008652

HO: $\mathrm{MSCl}$ do not Granger-cause BSE_Health

F-Test $=1.3216, d f 1=1, d f 2=206, p$-value $=$ 0.2516

\section{Table 5: Robust Regression Results}

BSE_Health diffEPU

\begin{tabular}{|c|c|c|c|c|}
\hline & $\begin{array}{l}\text { Coeffic } \\
\text { ient }\end{array}$ & Std. Error & t value & $p$-value \\
\hline Intercept & 0.0164 & 0.0048 & 3.392 & 0.0009 \\
\hline diffEPU & -0.0002 & 0.0001 & -1.629 & 0.1063 \\
\hline
\end{tabular}

Table 6: Robust Regression Results

BSE_Health diffEPU + MSCI

\begin{tabular}{|llrll|}
\hline \multicolumn{7}{|c|}{$\begin{array}{l}\text { Coeffic } \\
\text { ient }\end{array}$} & Std. Error & t value & p-value \\
\hline Intercept & 0.014 & 0.0041 & 3.438 & 0.0008 \\
diffEPU & $6.16 \mathrm{E}-060.0001$ & 0.059 & 0.953 \\
$\mathrm{MSCl}$ & 0.3507 & 0.0515 & 6.81 & $6.49 \mathrm{E}-10$ \\
\hline
\end{tabular}

Table 7: Johansen Test Results

Levels of Significance

\begin{tabular}{|llllll|}
\hline $\begin{array}{l}\text { No. of Co- } \\
\text { integrating } \\
\text { Relationships }\end{array}$ & $\begin{array}{l}\text { Test } \\
\text { Statistic }\end{array}$ & $10 \%$ & $5 \%$ & $1 \%$ & $\begin{array}{l}\mathrm{p} \text { - } \\
\text { value }\end{array}$ \\
\hline$r<=2$ & 36.8 & 10.49 & 12.25 & 16.26 & 0.001 \\
$r<=1$ & 87.15 & 22.76 & 25.32 & 30.45 & 0.001 \\
$r=0$ & 172.4 & 39.06 & 42.44 & 48.45 & 0.001 \\
\hline
\end{tabular}

Table 8: Vector Error Correction Model

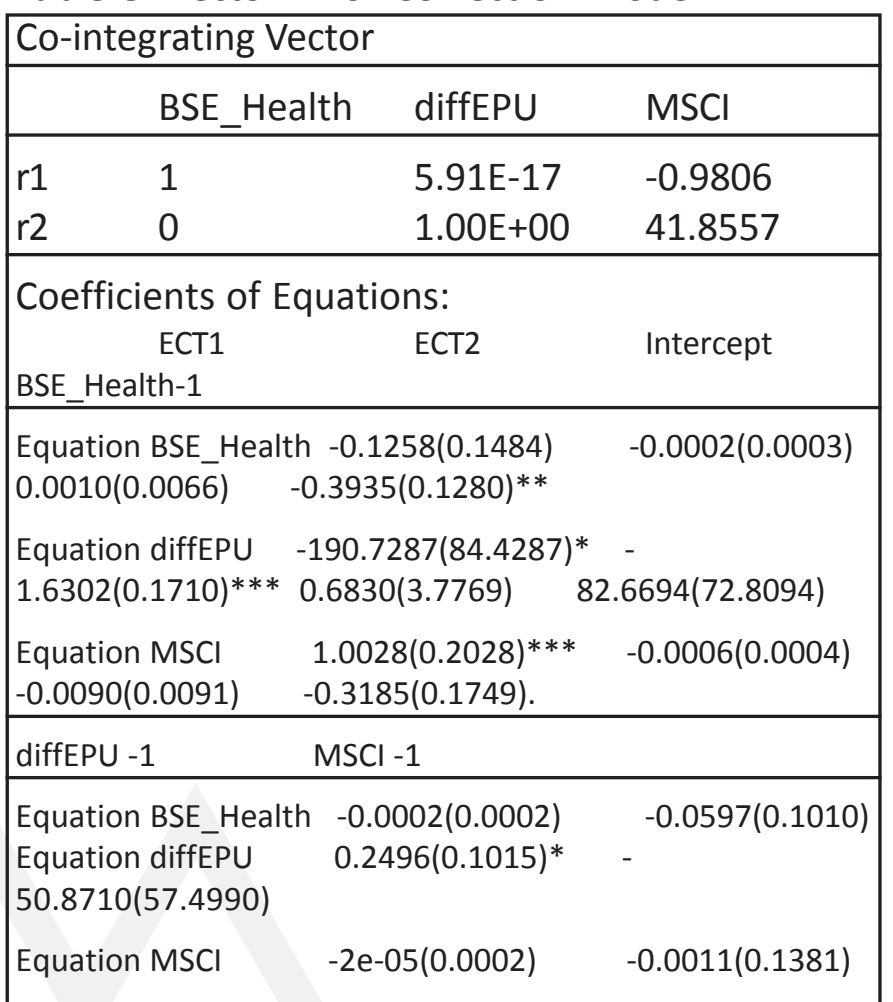

Note: $* * *, * *, *$ indicate significance at the $1 \%, 5 \%$ and $10 \%$ levels.

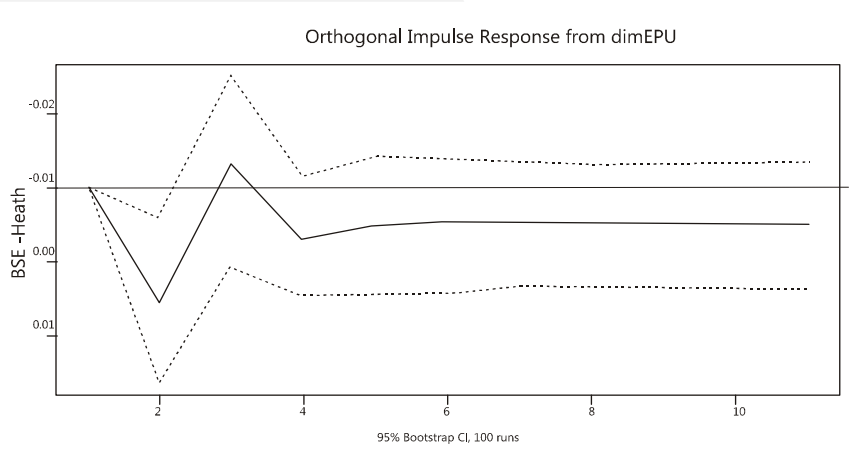

Figure 1

\section{Conclusion}

It can be concluded that there is evidence of a causal relationship between EPU index and the returns on BSE Healthcare Index as seen from the results of the Granger Causality tests. Also this negative relationship is reinforced from the Impulse Response Analysis carried out after constructing the Vector Error 
Correction Model (VECM). This is evidence to show that the state of the Indian pharma sector indicated by the BSE Healthcare index depends on a stable economic policy climate in India.

The results of the Robust Regression have been found to be contrary to that of the Granger Causality tests. One can conclude from this that the regression analysis does not necessarily imply a causal relationship between the variables, in this case EPU Index and returns on BSE Healthcare Index. This paper provides evidence to show that Granger Causality test coupled with the Impulse Response Function (IRF) analysis can be effectively used to test for presence of a causal relationship provided it is validated by supporting theory.

\section{References}

1. Baker, S., Bloom, N., \& Davis, S. (n.d.). Measuring Economic Policy Uncertainty. SSRN JournalSSRN Electronic Journal. doi:2012

2. Enders, W. (1995). Applied econometric time series. New York: Wiley
3. Gujarati, D. (2003). Basic econometrics. Boston: McGraw-Hill

4. Hermes, N., \&Lensink, R. (n.d.). Capital flight and the uncertainty of government policies. Economics Letters, 377-381. doi:2001

5. Hyndman, R. J., \&Athanasopoulos, G. (2013, October 17). 9.2 Vector autoregressions.

Retrieved January 23, 2017, from https://www.otexts.org/fpp/9/2

6. Pfaff, B., Dr., \& Taunus, K. I. (2007, September 09). Using the VARS package. Retrieved January 23, 2017, from http:// ftp.unbayreuth.de/math/statlib/R/CRAN/doc/ vignettes/vars/

7. Pfaff, B. (2016). Financial Risk Modelling and Portfolio Optimization with R (2nd ed.). Wiley

8. Pindyck, R. (n.d.). Irreversibility, Uncertainty, and Investment. WP\#3137-90-EFA. doi:March 1990 